\title{
Event study in Economics
}

\author{
Jeevan Jayant Nagarkar ${ }^{1}$, Viraja p Bhat ${ }^{2}$ \\ \{ jeevan.nagarkar@siib.ac.in ${ }^{1}$,viraja@siib.ac.in $\left.{ }^{2}\right\}$
}

Symbiosis Institute of International Business Sr No 174/1 Phase 1, Hinjewadi, Pune Maharashtra

\begin{abstract}
Event Studies is known to tolerate a long history in the ambit of investigation of fund and financial aspects. The main production on occasion think about was made by James Dolley in the year 1933 and in his examination; he analysed the value impacts because of occasions, for example, stock parts, considering ostensible value varieties over the span of the parts. Utilizing a thorough example of 95 stock parts amid the periods somewhere in the range of 1921 and 1931, he examined that stock costs expanded in 57 of the cases and the stock costs declined in the rest of the cases. Amid these decades from the mid-1930s to the late 1960s, the dimension of multifaceted design and refinement towards the idea of occasion think about steadily expanded in multi-folds. Throughout the years since these spearheading research examines, various alterations have been produced and crude methods have been ramified to join the changes identifying with the difficulties which emerge out of infringement in factual suppositions utilized in the early work and identify with modifications in the structure to oblige explicit theories.
\end{abstract}

Key Words: Event Study, Commercial Banks, Recapitalization, Asset Quality

\section{Introduction}

In more extensive sense, occasion examine has a few applications in the field of fund and bookkeeping research wherein it has been utilized to investigate an assortment of firm explicit and economy wide occasions. A few models incorporate mergers and acquisitions, profit declarations, issues of new obligation or value and declarations of full scale monetary factors, for example, the exchange deficiency. Be that as it may, occasion think about applications in different fields are likewise bottomless; for instance, occasion contemplates are utilized in the field of law and financial aspects to gauge the effect of any prospective changes in the administrative and statutory condition. In lawful risk cases, occasion contemplates are used to determine the harms caused to the separate gatherings. In the immense number of situations where occasion examines are being utilized, head center has been given around the impact of an occasion on the cost of a specific classification of securities of the firm, most ideally known as regular value.

\section{Literature Review}

The monetary econometric plan of an event study can be very much clarified with respect to the case of a solitary stock-occasion day mix. Considering a speculative precedent, assume that right away preceding to a merger declaration, a business insider with avenue to private data purchases a substantial stake of the organization's offers fully expecting a stock value upgrade 
on the day of the merger declaration. In a tumultuous continuing, it should have been demonstrated that the insider tangibly profited by the avenue to the private data. Such an incident may be exhibited by appearing on the merger declaration day, the stock cost delighted in a huge increment in esteem. Event Study systems are normally acknowledged as proof in choosing if insiders profited from the utilization of private data and also in deciding the greatness of their benefit.

To outline how occasion think about proof may be exhibited in an insider-exchanging scenario, suppose 'Day-Zero' recognize the merger declaration day under investigation and let subsequent days $\mathrm{T}=\ldots 4,3,2,1$ speak to exchanging the number of days paving the way to the occasion. A gullible study on events may contrast the occasion day return R0 and returns saw amid a period of control before the occasion. In the event that the occasion date return R0 was factually vast contrasted with pre-occasion control period returns, we may infer that the occasion had a noteworthy stock value affect. In any case, this guileless correlation of the occasion day return R0 with pre-occasion day returns do not unravel the impacts of business-explicit data from broad market data influencing the stock cost.

A progressively complete strategy utilizes the market model to modify the occasion date blend come back to expel the impact of the general market. Numerically, the market show utilized in occasion ponders is indicated in condition (1), where $R_{t}$ and $R M_{t}$ signify the arrival on day ' $t$ ' for the stock and the general market, individually, ' $t$ ' and ' $e$ ' speaks to a firm-explicit return, and the characters, a, b determine the straight structure of the display of the market.

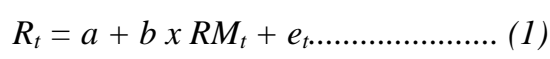

By suppositions inborn in the dynamics of the market demonstrate, the business-explicit return ' $\mathrm{t}$ ' and ' $\mathrm{e}$ ' is irrelevant to the general market scenario and has a normal estimation of 0 . Subsequently, the normal occasion day-return contingent on the occasion date showcase return is,

$$
E\left(R_{0} \mid R M_{0}\right)=a+b \times R M_{0}
$$

By adjusting the observed event day-return R0 by deducting the conditional expected return yields an unusual return specified in equation (3). Notice that the unusual return A0 is simply the Day- 0 business-specific return $0 \mathrm{e}$, which is identified by the model of the market in equation,

$$
A_{0}=R_{0}-E\left(R_{0} \mid R M_{0}\right)=R_{0}-a-b \times R M_{0}
$$

Most of the examples of event studies contain an example comprising of different stockoccasion day mixes, in which case, it is attractive to total outcomes in to a solitary speculation test. For instance, an insider-exchanging situation may include different stock-occasion day mixes.

The essential undertaking of directing a theory for an occasion ponder is to characterize the occasion of enthusiasm for inquiry and distinguish the period amid which the security costs of the organizations associated with this occasion will be considered-the occasion window. For instance, on the off chance that one is taking a gander at the data substance of profit per share with every day information, the occasion will be the income declaration and in particular the occasion window will incorporate the separate day of the declaration. It is standard to outline the occasion window to be more noteworthy than the particular time of enthusiasm for inquiry. 
This permits the point by point examination of periods encompassing the occasion. Practically speaking, the time of intrigue is frequently organized to different days, comprehensive of at any rate the day of the declaration and the following day after the declaration. This visualizes the value impacts of revelations which happen after the share trading system closes on the declaration day. The lengths preceding and after the occasion may likewise be of intrigue.

For instance, in the Earnings Per Share declaration case, the market may recover data about the income of the firm before the genuine declaration and one can research and dissect this plausibility by looking at pre-occasion returns. For instance, in an occasion think about utilizing day by day information and the market demonstrate speculation, the market show parameters could be assessed over the 120 days preceding the occasion. By and large the occasion time frame itself isn't engaged with the estimation time frame so as to keep the occasion from affecting and affecting the ordinary execution demonstrate parameter gauges and figures. With the parameter gauges for the typical execution display, the irregular returns of the said occasion can be determined and evaluated and thus, the plan and structure of the testing system for the unusual returns. A few imperative contemplations are characterizing the invalid speculation and finding out the procedures for totalling the individual company's strange returns.

To encourage the examination of the effect of the income declaration on the estimation of the association's value, it is basic to place the connection between the data discharge and the adjustment in estimation of the value. In this precedent the errand is direct. On the off chance that the income divulgences have data explicit substance, more prominent than anticipated profit ought to be related with increments in the estimation of normal value and lower than anticipated profit with declines in estimation of basic value. To catch this amalgamation, every declaration or assertion is doled out to one of three classifications: uplifting news, no news, or terrible news. Each declaration is arranged and isolated utilizing the deviation of the genuine profit from the normal income. Of the 600 declarations recorded, 189 are uplifting news, 173 are no news, and the staying 238 are awful news from the all-out data gathered.

The Financial Accounting Standards Board (FASB) and the Securities Exchange Commission (SEC) endeavour to set detailing controls and statutory standards with the goal that budget reports and investigations related data discharges are enlightening and convincing about the estimation of the firm. In setting models, the data content assembled of the monetary revelations is of fundamental intrigue. Occasion ponders give a perfect apparatus to inspecting the data substance of the divulgences distributed by the overseeing bodies.

\section{Objectives}

- $\quad$ One of the most vital objectives of this research paper is to form a comprehensive analysis of the subject of Event Studies with respect to Economics and Finance and understand its effect on the economy in general.

- In order to make an in-depth analysis of Event Studies, categories of such incidents are taken into account such as the rift between the RBI and the Government of India and the subsequent consequence of that event on the economy is analysed.

- To broadly perceive the discussion on the stand-off between the RBI and the Government of India on the joint custody of surplus funds of Rs. 3.6 lakh crores, 
proper understanding of the statutory framework needs to be achieved to understand this proposition.

\section{Research Methodology}

The research paper would be broadly based on the methodology of secondary data and the information available for public knowledge on the website of the RBI. Since the ultimate objective of this research paper is to substantiate the concept of Event Studies by using the example of the on-going rift between the RBI and the Central Government of India, The objectives of the study have been addressed using a comprehensive approach by extracting data about the relevance of event studies in the practical environment.

\section{Data collection and Analysis}

Clashes between national banks and governments are inserted in the developing talk of each majority rules system. The ongoing disagreement between the RBI and the Ministry of Finance (MoF) in the earlier year 2018 is neither the first nor liable to be the last. Institutionally, when a difference between the RBI and the MoF crosses the Rubicon, the legislature has the ability to overrule the national bank's choices. In addition, such a structure isn't limited to the RBI however applies to all controllers, regardless of whether monetary or non-money related. In its law-production intelligence, Parliament has chosen that since responsibility rests with a chose government and not the master official, so should powers. To contend generally may be a political talk and won't stand the trial of law. This paper presents the defence that since the RBI's most essential money related approach work has been secured by law through the setting up of the Monetary Policy Committee, all choices past it fall inside the domain of 'responsibility', where the chose government has been empowered, again by law, to mediate when required. Occasion thinks about pursues a connection between the spat of the RBI and the Central legislature of India which demonstrates the whole establishment of this examination.

The RBI-MoF struggle - profoundly open and furiously political—saw authorities from the two organizations participate in a skirmish of turfs through authority addresses, official statements, and internet based life explanations. Against this foundation, the time has come to re-evaluate and discuss the bigger issues around institutional administration and its working inside the opportunities and limits of India's ground-breaking vote based system. While such clashes might be 1 unavoidable given the "common pressures" between money related approaches drafted by national banks and financial arrangements planned by governments, the discussion around these contentions appears to have been encircled around the 'David and Goliath' symbolism. In the Indian setting, this is deceiving.

The supposed tricks that were empowered by either free directions or degenerate practices, or both, at open part banks (PSBs) have offered ascend to inquiries regarding the effectivity of the RBI as India's managing an account controller. The authorities, the administrations and even the Boards of PSBs appeared to be either ignorant or complicit, as realized identities supposedly redirected cash, the most prominent being Vijay Mallya and Nirav Modi. Preliminaries are yet to start, and the courts must govern on whether these supposed cheats were in truth wasteful aspects, terrible business choices, or criminal intrigues. On their part, Opposition parties have 
raised the issue of administrative complicity, referring to the instances of both Vijay Mallya and Nirav Modi. Thus, the legislature faulted banks and examiners, 4 just as the RBI. With a half year to go before decisions, the contention has progressed toward becoming as much political as it is monetary, money related or administrative - with the previous nearly muffling the last mentioned.

\section{Loss-Absorption Role of Bank Capital}

The objective of Basel III Accords is to uplift the aspect, coherence and straightforwardness of the base of the capital of banks to endure the unexpected misfortunes and also to fortify the general hazard inclusion of the structure of capital. Notwithstanding updating the base capital proportion prerequisites for credits hazard, Basel III norms additionally presented a Capital Preservation Cradle (CPC) and a counter-cyclical support of capital. Capital Preservation Cradle is intended to guarantee that banks develop a cradle of capital outside times of money related pressure that can be brought drawn down when banks confront budgetary (foundational or peculiar) push. Banks which bring down their capital preservation support amid are focused on a particular period are necessitated to keep a positive intend to recharge the cradle and withstand capital dissemination imperatives. The target of the counter-cyclical capital support is to utilize capital as a large scale instrument of prudence which went for shielding the managing an account segment from times of abundance total credit development, that have regularly been related with the development of framework wide hazard.

In such manner, it requires to be educational to take idea of the fact that base bank capital proportion (to reasonably hazard weightage-given resources) are necessitated to be held under the Basel regulations is just a story. As the worldwide monetary emergency, numerous nations need their banks to hold capital at more elevated amounts, as appeared as follows. Moreover, in other significant locales like the UK and the US, compelling capital prerequisites will in general be much higher because of a few additional items; for example, in the country of US, the higher the use proportion (to explain simply, bank money to un-weightage-given resources proportion) and the pressure examinations - yearly Comprehensive Capital Analysis and Review (CCAR) - likewise enhance the viable capital necessities past Basel prerequisites for fundamentally imperative as well as vast banks.

\section{RBI's Regulatory Prompt Corrective Action (PCA)}

Prompt Corrective Action systems receive the central standards of organized early mediation and goals in the accompanying way:

i. Thresholds of execution, in the event of FDIC (Federal Deposit Insurance Corporation), bank capitalization, are recognized to characterize banks that break the edges into classes, for example, on account of FDIC into "under-promoted", "altogether under-promoted" and "fundamentally under-promoted". The main edges are set at levels that are well above what might take into account a compelling goals or recovery of banks.

ii. Banks that don't accommodate the limits are exposed to a stratified, continuously strict "program", comprising of compulsory \& optional administrative activities, which is intended to forestall future draining, successfully isolating the banks in break until the point that they are settled. Another essential basis is to enable chiefs to implement 
restorative measures in a standard based way and along these lines lessen the danger of patience.

iii. Thus, the extent of compulsory activities over all hazard edges has been limited basically to:

○ Restriction on profit conveyance/settlement of benefits;

- Requirement on advertisers/proprietors/guardians to acquire progressively capital;

- Reservations on extension of branches;

○ Enhanced provisioning necessity; \&,

○ Contractions on the board remuneration.

\section{Performance of the PCA Banks in India}

By and by, there are twelve banks, eleven in people in general part and 1 in the private sector, under the RBI's revised 'PCA' Framework, with 'PCA' having been forced on them between the period of February 2014 and January 2018. The offer of these 'PCA' banks in advances and stores as on 31 st March, 2018 was 18.5 percent and 20.8 percent, separately.

\section{Re-Capitalization}

The declining pattern of 'CRAR' and Tier-One capital proportion for 'PCA' banks that began in the year 2011 has been captured and the proportion has been continued relentlessly since the years 2014 at or higher than globally endorsed dimensions. It might, notwithstanding, be noticed that the 'PCA' banks have had to bring down 'CRAR' and Tier-One capital proportions contrasted with non- 'PCA' banks excepting the year 2011), \& particularly private banks (directly since the year 2009).

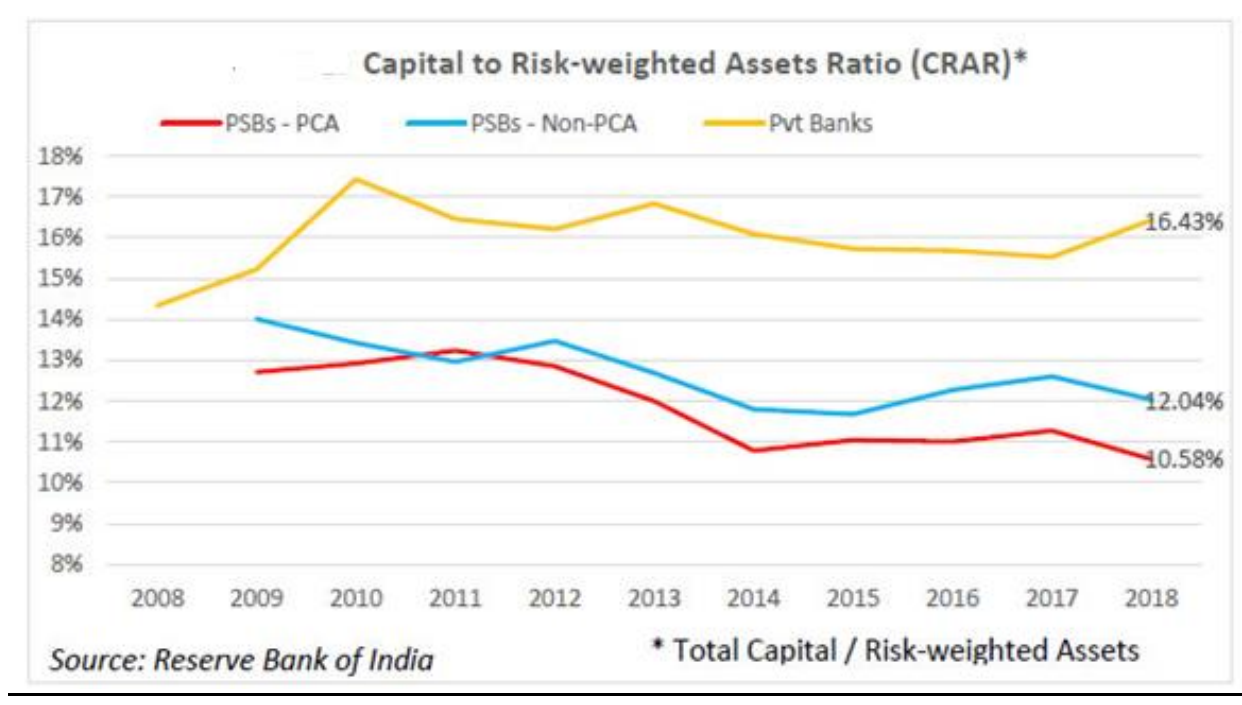

Fig.1. Capital to Risk- Weighted Assets Ratio 


\section{Quality of Assets}

Compiling together the Gross and Net NPA proportions of 'PCA' banks exuberate those of non'PCA' banks up until the time around the year 2014. Notwithstanding, post the 'Asset Quality Review' (AQR) work out, the NPA acknowledgment at 'PCA' banks has prompted a more keen ascent in both Gross and Net NPAs, with respect to non- 'PCA' banks, and particularly in respect to Private Banks. However, such a situation does not imply that 'AQR' caused the NPAs; it basically actuated the long-past due acknowledgment of NPAs. Prominently, the focused on resources proportion, which other than NPAs incorporates the Restructured Standard resources (that delighted in the administrative self-control under the prior rules), uncovers that the hidden resource sufficiency at 'PCA' banks was disintegrating at a more keen speed contrasted with non-'PCA' banks directly since the year 2011, wherein, this is currently acknowledged as a time with which the loaning blast of the yeasr 2009-10 started to unwind.

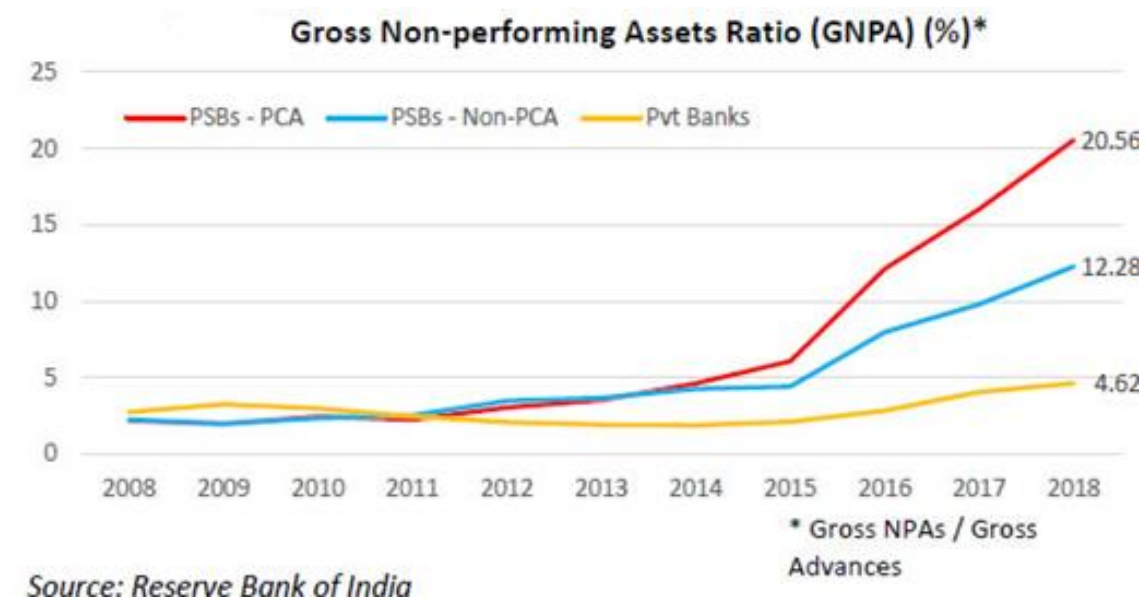

Fig. 2. Gross Non- Performing Assets Ratio (\%)

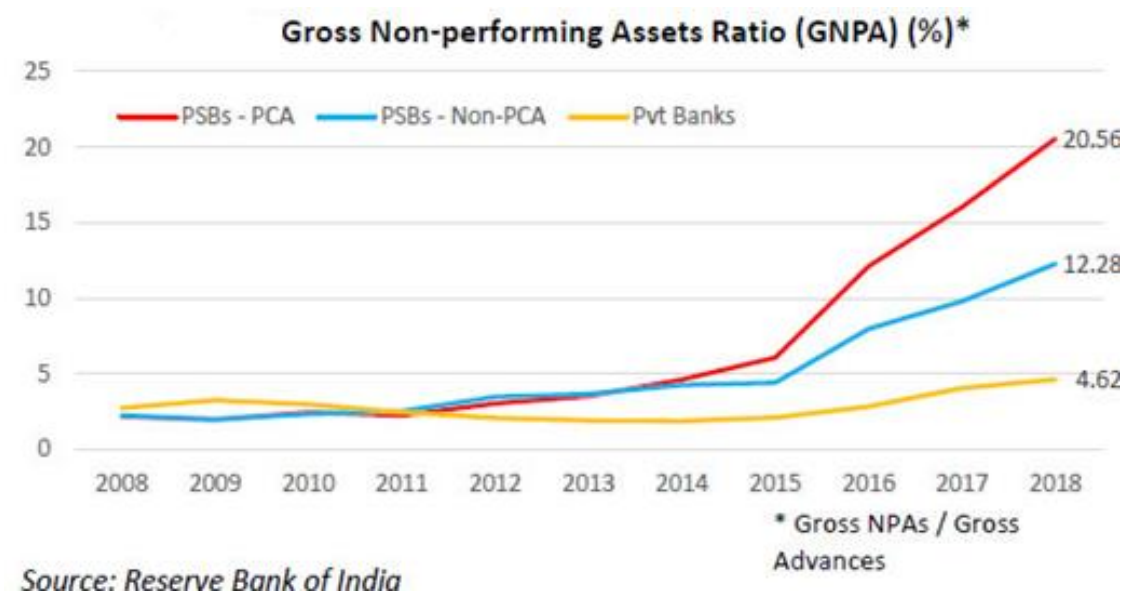

Fig.3.: Net Non performimg Assets ratio 


\section{Re- Capitalization}

The Indian Government has injected more than rupees twenty-three hundred billion openly across Banks since the year 2005, the greater part of which has been absorbed by banks which are as of now under 'PCA'. Inside 'PCA' Banks, practically 50\% of the all-out imbuement (i.e., rupees six hundred and thirty-five billion) has happened amid FY-2018 \& FY-2019, post the banks were arranged under 'PCA'. This recapitalization has been a vital supporter of money related strength of these banks and of whatever is left of the managing an account framework they manage.

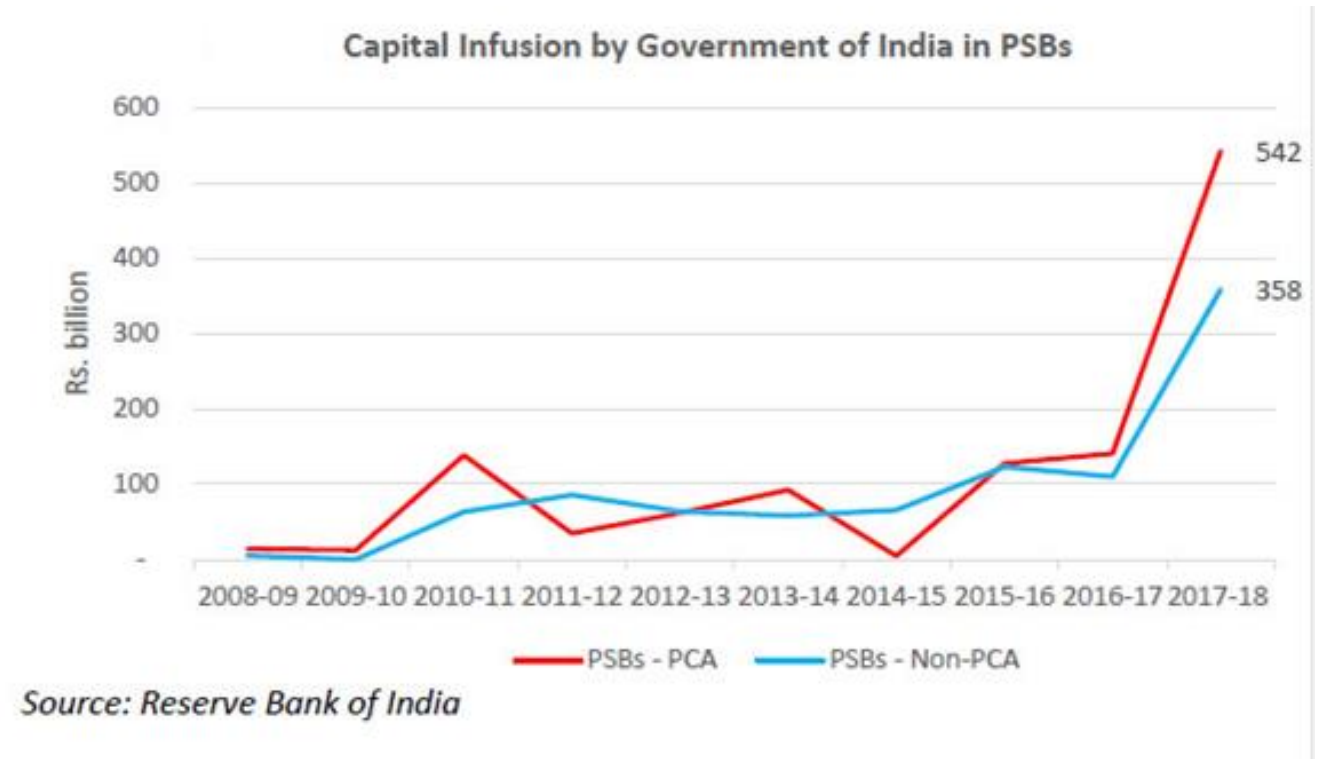

Fig.4: Capital Infusion by Government Of India fom FY 2008-18

\section{Governance By The Accountable Or Primacy Of The Government}

India's national bank was made under the Reserve Bank of India Act, 1314 1934, which in addition to other things, drills down its capacities, synthesis 15 of the focal board, term of office of executives and (explicit to the present contention) the intensity of the legislature to offer bearings to 16 the RBI. The risk by the administration to utilize Section 7 under Chapter II of the Act was translated by a segment of investigators as trespassing on the national bank's turf. In any case, a straightforward perusing of the law puts the legitimate powers unmistakably in the hands of the administration.

The Central Government may every once in a while, give such headings to the Bank as it might, after discussion with the Governor of the Bank, think about essential in people in general premium," Clause 1 of Section 7 states. The following condition combines this power: "Subject to any such headings, the general superintendence and course of the issues and business of the Bank [RBI] will be endowed to a Central Board of Directors which may practice all forces and do all demonstrations and things which might be practiced or done by the Bank." Thus, if the 
administration sees issuing bearings as an issue of open premium, it does as such dependent on the forces permitted it by the law. While for the most part detailed through anonymous authorities and hence unattributed, the administration had been thinking about the utilization of Section 717 through three letters. In the interim, and dependent on similar terms of anonymous sources, it was additionally detailed that RBI Governor Patel would be 18 offering his renunciation.

The inquiry that must be addressed is the point at which the legislature should utilize this power. "Such a power ought to be compelled," and it ought to be "totally obvious to the official, lawmaking body, and the overall population that obligation regarding the outcomes lies with the legislature, not the national bank, if the national bank is overruled, its recommendation disregarded, or its 19 viability is altogether constrained by government strategies." Even before the RBI and the administration started to talk at one another through the media, this correspondence breakdown had been developing. Under strain because of the Opposition's surrounding of the asserted Nirav Modi trick as proof of the administration's defilement, Finance Minister Arun Jaitley drove the administrative mantle towards the 20 administrations of PSBs, evaluators and RBI. "Controllers eventually choose the tenets of the amusement and controllers must have a third-eye which is to be unendingly open," he said. The RBI's answer came three weeks after the fact, in a 21 address by Governor Patel, in which he strikingly expressed, "Saving money Regulatory Powers in India are not Ownership Neutral." He gave seven examples of administrative requirements the RBI faces while controlling PSBs. Utilizing a similarity of the Devas and the Asuras in the Amrit Manthan, Patel looked to level the administrative playing field among PSBs and private-area banks.

As the discussion on controlling PSBs proceeded and weights of quietness between the national bank and the legislature expanded, RBI Deputy Governor Viral V. Acharya raised the contribute and opened another flank the fight. "Governments that don't regard national bank autonomy will sometime bring about the rage of budgetary markets, touch off financial fire, and come to lament the day they undermined a 24 critical administrative establishment," he said. "Their more astute partners who put resources into national bank autonomy will appreciate bring down expenses of acquiring, the adoration for global financial specialists, and longer life expectancies." The planning of this discourse -24 days to the RBI focal executive gathering in the midst of the progressing pressures - fanned the fire and was generally observed as political showing off and uprightness motioning than commonsense worry for 'freedom'.

\section{Accountability To The People Versus Tyranny Of The Unelected Expert}

The discussion around the centrality of national financiers depends on single word: "Independence". This thought was made and assembled energy during the 1980s and "it ended up chic to formally ensure the self-sufficiency of the national bank vis-à-vis the legislature, just as giving national banks express (or understood) quantitative expansion 38 targets." What has risen as an unintended outcome is the contention between national banks and governments. Settling these discussions rests around another thought: responsibility. In many popular governments, governments confront the results of terrible money related arrangement choices by being casted a ballot out, while controllers develop sound. However, in the event that responsibility rests with the administration, the forces ought to as well. A situation, where selected master authorities can secure themselves against all scrutinizing behind the shield of 
'autonomy' and leave the messy activity of responsibility to the legislature flourishes just in creative energy.

\section{Findings and Conclusion}

The very premise of Event Studies rests on the fact that a particular incident could potentially cause a widespread effect on investor confidence and thereby shake the very foundation of a specific business corporation or a country for that matter. While matters between the central Government of India and the Reserve Bank of India caused great uncertainty and ambiguity in the financial markets, stock prices of several corporations witnessed a massive blow and the already bleeding Indian stock markets faced a nation-wide outcry over their investments.

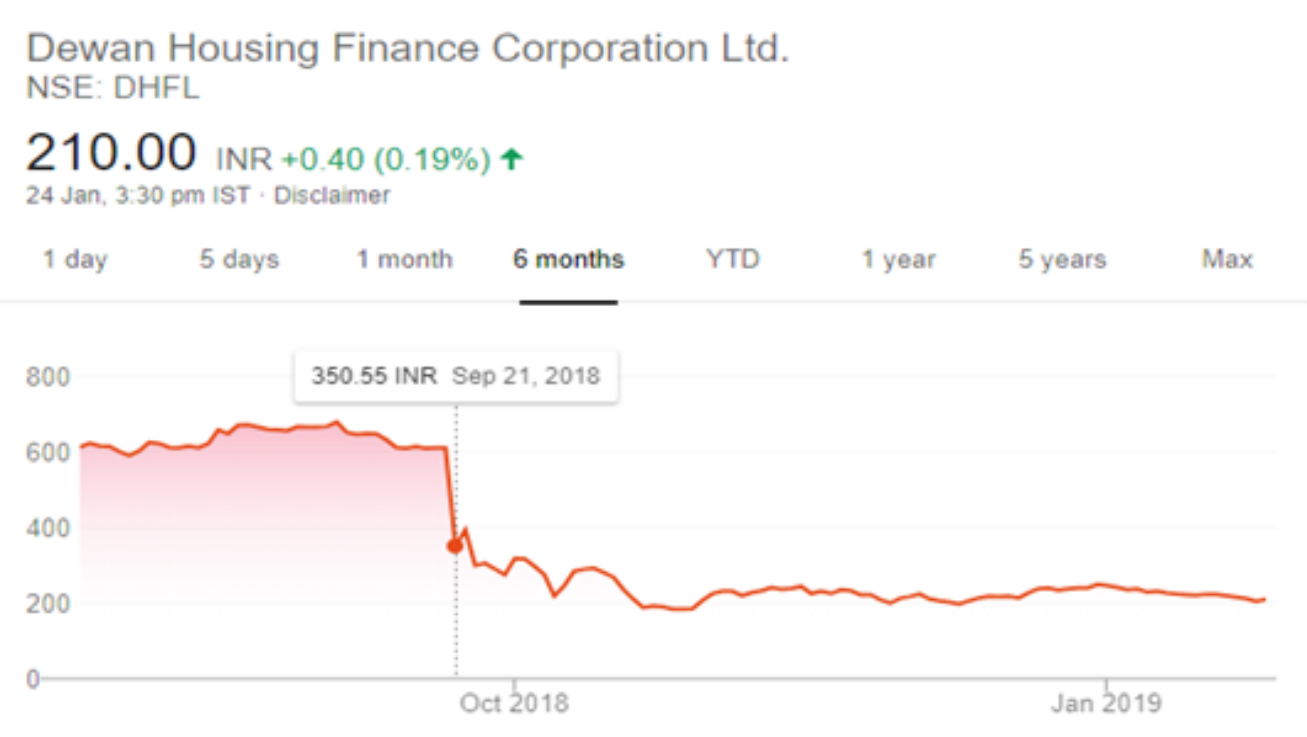

Fig. 5. Sudden Price Movement at Dewan Housing Finance Corporation Ltd. ( Sep'18 to Jan'19)

Fig.5. indicates that due to a company specific news there has been a random change in the share prices of Dewan Housing finance in the period October 2018 till Jan 2019 ranging between Rs. 600 to Rs. 200. On the event day

(Sep 21, 2018 ) it was observed that the share price reached Rs. 350.55 which can be attributed to the news . 


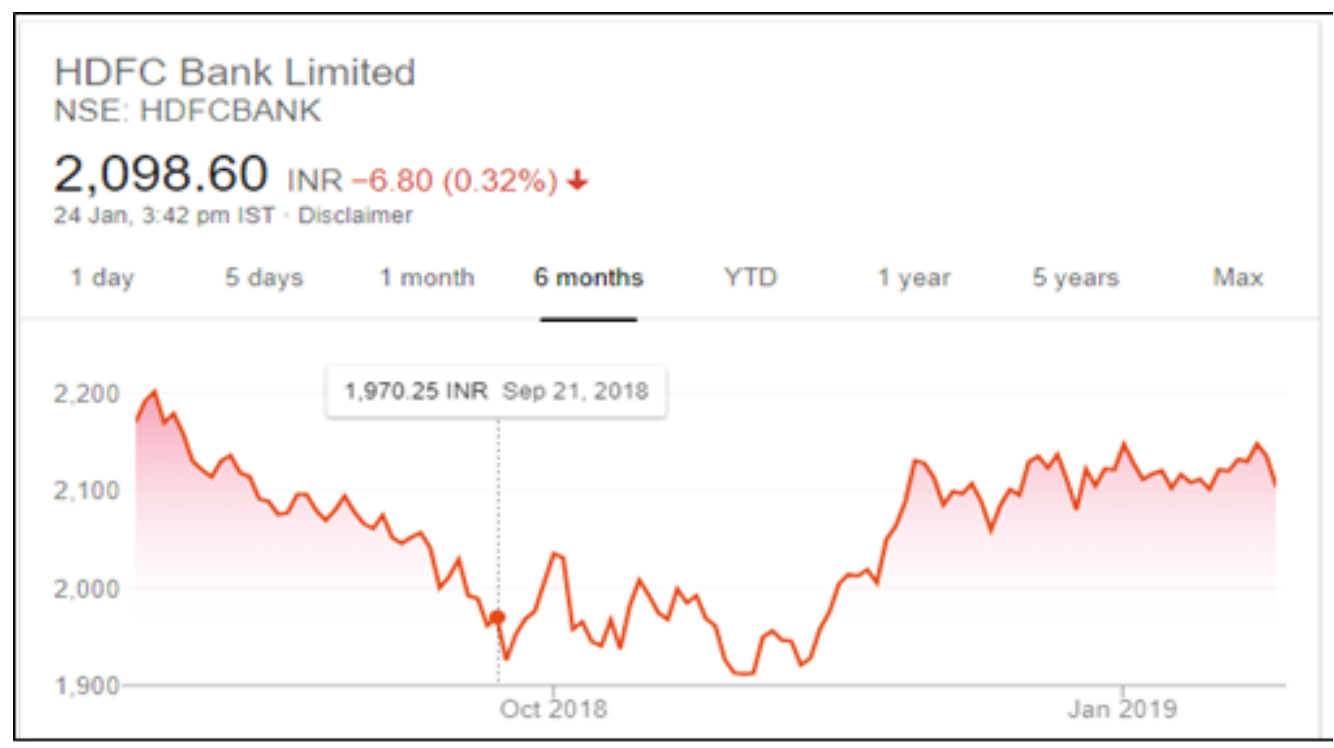

Fig. 6. Sudden Price Movement at Housing Development Finance Corporation Bank . ( Sep'18 to Jan'19)

Fig.6. indicates that due to a company specific news there has been a random change in the share prices of HDFC Bank Limited in the period October 2018 till Jan 2019 ranging between Rs. 2200 to Rs. 1900 to Rs. 2200. On the event day (Sep 21, 2018 ) it was observed that the share price reached Rs. 1970.25 which can be attributed to the news temporarily and it attained the gain very quickly and reached Rs. 2200 again. So, it can be observed that the impact was comparatively negligible in case of HDFC. .

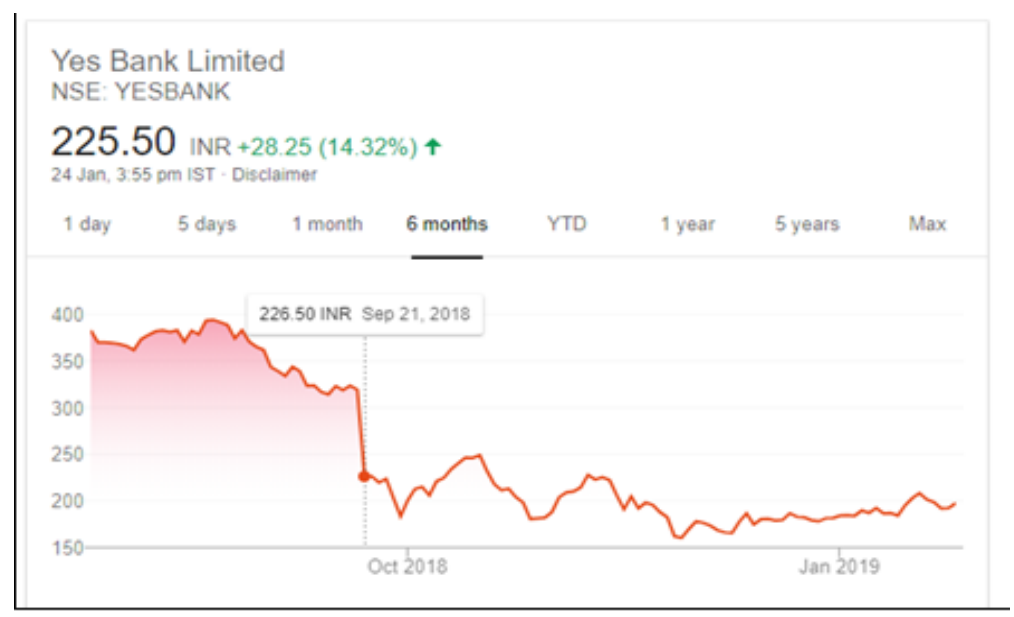

Fig. 7. Sudden Price Movement at Yes Bank Limited ( Sep'18 to Jan'19) 
Fig.7. indicates that due to a company specific news there has been a random change in the share prices of Yes Bank Limited in the period October 2018 till Jan 2019 ranging between Rs. 380 to Rs. 175. On the event day (Sep 21, 2018 ) it was observed that the share price reached Rs. 226.50 which can be attributed to the news .

From the share price observation on the event day and based on the data representation in Fig 5-7, it can be observed that the impact has been significant for Diwan Housing Corporation and Yes Bank Limited whereas HDFC Bank Limited has a negligible impact.

\section{Conclusion}

While the facts demonstrate that the RBI- government struggle is presently before, this was, in no way, shape or form, the last such experience. All things considered, the universe of administrative foundations and their administration is continually advancing; it reflects the market, the players, the purchasers; and it changes to adjust. With innovations likewise having a multifaceted effect in the public arena, there is no motivation to trust that administrative establishments will stay unaffected. Clashes are presently inserted in the national bank and the administration relationship; they are not bad, but at the same time not enough to blow anyone's mind.

As operators of progress, it basic that the legislature convey advantages to society. The political economy of each majority rules system guarantees that motivations are lined up with this change. Then again, controllers, for example, the RBI are driven by standards and directions, solidness and liquidity, loan costs and expansion focusing on. While the legislature has the ability to issue headings just as change the board, it must do as such with extraordinary alert and give the RBI the adaptability to work inside the ambit of its imperatives. Both the administration and the RBI must keep away from breakdowns in correspondence. Given that egos, inclinations, and unique perspectives on issues of arrangement do exist, there is a requirement for more prominent affectability and regard on the two sides. Most importantly, any long-running open presentation of unfriendliness is essentially inadmissible from high-positioning authorities, as it pulls in only hatred from general society and erodes the validity of the foundations. The essence of the pressure, in this way, originates from an arrangement test to adjust two objectives:

1. Autonomy of the national bank from political obstruction, so it can embrace its money related approach and administrative duties uninhibitedly and with no weights. In India, this has now turned into the law through the production of the Monetary Policy Committee.

2. Responsibility of the financial framework, with the administration as of now holding that duty, the component of decisions making it liable.

Besides, concerning the subject of Event Studies, one can immovably concur that, budgetary markets and money related affinity of organizations vigorously depend on the data accessible with financial specialists which corresponds to Newton's Third Law of Motion which goes as: "Every action has an equal and opposite reaction." 


\section{References}

[1] https://pdfs.semanticscholar.org/aac6/83a678a12a3dcd73389aac7289868847ea73.pdf

[2] https://academic.oup.com/rof/article-abstract/20/4/1659/1752967

[3] https://rbi.org.in/scripts/BS_SpeechesView.aspx?Id=1067

[4] https://economictimes.indiatimes.com/markets/stocks/news/why-are-overseas-investorsunfazed-at-rbi-government-rift/articleshow/66435681.cms

[5] https://papers.ssrn.com/sol3/papers.cfm?abstract_id=1441581

[6]

https://www.researchgate.net/publication/229489156_Understanding_and_Conducting_Eve nt_Studies

[7] https://www.bbc.com/news/world-asia-india-46054042 